This is an author produced version of a paper published in Toxicology Letters. This paper has been peer-reviewed but does not include the final publisher proof-corrections or journal pagination.

Citation for the published paper:

Martin A Carnerup, Mårten Spanne, Bo AG Jönsson.

"Levels of $N$-methyl-2-pyrrolidone (NMP) and its metabolites in plasma and urine from volunteers after experimental exposure to NMP in dry and humid air".

Toxicology Letters, 2005, Nov 28.

http://dx.doi.org/10.1016/j.toxlet.2005.09.035

Access to the published version may require journal subscription.

Published with permission from: Elsevier 


\title{
Levels of $N$-methyl-2-pyrrolidone (NMP) and its metabolites in plasma and urine from volunteers after experimental exposure to NMP in dry and humid air
}

Martin A Carnerup, Mårten Spanne, Bo AG Jönsson

Martin A. Carnerup, $₫$ Bo A.G. Jönsson

Department of Occupational and Environmental Medicine, Institute of Laboratory

Medicine, Lund University Hospital, S-221 85 Lund, Sweden

Mårten Spanne

Department of Design Sciences, Division of Ergonomics and Aerosol Technology, Lund Institute of Technology, Box 118, S-221 00 Lund, Sweden

\author{
Correspondence: \\ Bo Jönsson \\ Department of Occupational and Environmental Medicine \\ Lund University Hospital \\ S-221 85 Lund \\ Telephone: +46-46-173186 \\ Telefax: +46-46-143702 \\ E-mail: bo.jonsson@ymed.lu.se
}




\section{Abstract}

The aim of this study was to investigate if the uptake of $N$-methyl-2-pyrrolidone (NMP), a widely used industrial chemical, increases after exposure to NMP in humid air compared to dry air. NMP has been described to be an airway irritant and a developmentally toxic compound. Six male volunteers were exposed to NMP, three at the time, for $8 \mathrm{~h}$ in an exposure chamber. They were each exposed on four different occasions to air levels of 0 and $20 \mathrm{mg} \mathrm{NMP} / \mathrm{m}^{3}$ in dry and humid air. Blood and urine were sampled before, during and up to 5 days after the end of the 8-h exposure. Plasma and urine were analysed for NMP and its metabolites, using liquid chromatographytandem mass spectrometry. There was no statistically significant increase in the total cumulated excretion of NMP and its metabolites in urine after exposure in humid air as compared to dry air. Furthermore, there were no differences in the levels of peak concentrations in either plasma or urine. Also, no differences were found in AUC between the exposures. However, there were large individual differences, especially for the exposure in humid air. A not previously identified metabolite in human, 2Pyrrolidone (2-P), was identified. The results do not support a significantly higher absorption of NMP at exposure in humid air as compared to dry air. However, the large individual differences support the use of biological monitoring for assessment of NMP exposure. In addition, 2-P was confirmed to be an NMP metabolite in humans. This may be of importance for the developmental toxicity of NMP since 2-P have been described to be a reproductively toxic substance. 


\section{Introduction}

$\mathrm{N}$-methyl-2-pyrrolidone (NMP, CAS number 872-50-4) is due to its physical properties a widely used industrial chemical. It is a small cyclic amide and it is totally miscible in water as in many organic solvents. NMP is powerful as a solvent and used in the petrochemical industry, as a reaction media in the polymer industry and as a formulating agent for inks, dyes and pesticides. It is used as a paint-stripper, as a stripping and cleaning agent in the microelectronics industry and for graffiti removal (IPCS, 2001).

Previous studies have showed that the human body readily absorbs NMP, both in the respiratory system ( $\AA$ kesson and Paulsson, 1997), the gastrointestinal tract (Åkesson and Jönsson, 1997) and through the skin (Akrill et al., 2002; Åkesson et al., 2004). NMP is hydroxylated to 5-hydroxy- $N$-methyl-2-pyrrolidone (5-HNMP)(Åkesson and Jönsson, 1997), partly by the enzyme cytochrome P450 isoform 1E (CYP1E)(Ligocka et al., 2003). 5-HNMP is oxidised to $N$-methylsuccinimide (MSI) and then further hydroxylated to 2-hydroxy- $N$-methylsuccinimide (2-HMSI)( Åkesson and Jönsson, 1997). 2Pyrrolidone (2-P) has been found to be a metabolite in rats (Carnerup et al., manuscript).

Analytical methods for the determination of NMP and its metabolites have been developed (Åkesson and Paulsson, 1997; Jönsson and Åkesson, 1997; Carnerup et al., 2001) and the possibilities to use these compounds as biomarkers of NMP exposure have been presented (Åkesson and Paulsson, 1997; Åkesson and Jönsson, 2000; Jönsson and Åkesson, 2001, 2003).

NMP has been reported to be a developmentally toxic compound to rats after both inhalations, dermal and oral administration (Becci et al., 1982; Saillenfait et al., 2002 and 
2003). A human stillbirth after a single exposure including skin contact, to an unknown level of NMP has also been described in a case report (Solomon et al., 1996; Bower et al., 1997).

The potency of NMP to induce airways diseases and other systemic health effects are unclear. One study reported headache and irritation to the respiratory system and to the eyes after an occupational exposure as low as $3 \mathrm{mg} / \mathrm{m}^{3}$ (Beaulieu and Schmerber, 1991). Langworth et al. (2001) reported headaches and irritation to the skin and eyes and the upper airways among graffiti removers exposed to mixtures of NMP and glycol ethers. However, in another study where volunteers were experimentally exposed to NMP air levels of $50 \mathrm{mg} / \mathrm{m}^{3}$, no such effects were reported (Åkesson and Paulsson, 1997). Some symptoms may be explained by peak exposures to NMP or cross exposure to other compounds within the industry while other symptoms may be explained by an extensive dermal absorption of NMP. In a study where Swedish graffiti removers working with NMP-containing cleaning agents, dermal absorption was suggested to play an important role on the development of irritation (Anundi et al., 2000). Furthermore, the importance of the dermal absorption have been showed in studies where rats exposed head only to $1000 \mathrm{mg} \mathrm{NMP} / \mathrm{m}^{3}$ only showed irritation to the respiratory system, while whole body exposure to the same concentration, caused severe effects on major organs and an extensive mortality. The importance of the relative air humidity $(\mathrm{RH})$ was also shown in these studies. Whole body exposure to $1000 \mathrm{mg} \mathrm{NMP} / \mathrm{m}^{3}$ in dry air caused some sensory irritation while whole body exposure to the same concentration in air with high relative humidity caused a slight decrease in white blood cells and lymphocytes, increased liver and lung weight and nasal irritation symptoms (IPCS, 2001). However, it should be 
emphasised that in these studies there were probably also a high oral uptakes from fur cleaning.

In this study we investigated the toxicokinetics of NMP and its metabolites after air exposure to NMP at two different levels of air humidity. We also investigated whether 2$\mathrm{P}$ is a human metabolite. 


\section{Material and methods}

\subsection{Subjects}

Six healthy male volunteers (subjects 1-6, age 22-59 years) were studied. The participants were subject to a general health examination prior to the study, with special attention to liver, kidney and haematology. The study was approved by the ethics committee at Lund University (LU 180-01, Faculty of Medicine, Lund University, Sweden), and all six subjects gave their written informed consent to participate in the study.

\subsection{Exposure chamber and exposure}

The exposure chamber was made of stainless steel, had a volume of $18 \mathrm{~m}^{3}$ and an air exchange rate of $2.0 \mathrm{~h}^{-1}$. Particle free air with a regulated temperature and humidity was introduced into the chamber from the ceiling. Pure NMP was continuously vaporised in a heated $\left(200^{\circ} \mathrm{C}\right)$ round-bottomed flask that was continuously flushed by a small stream of dry particle free air. The vaporised NMP was then introduced in the air inlet of the chamber. The relative air concentration of NMP inside the chamber was continuously measured with an infrared spectrophotometer (Miran-1a, wavelength $7.75 \mu \mathrm{m}$, path length $20.5 \mathrm{~m}$ ). Particles of sodium chloride, generated by a nebuliser using a $0.05 \%$ sodium chloride solution, were introduced into the chamber to act as condensation nuclei for the NMP vapour. The amount and size distribution of particles inside the chamber were continuously measured using a Scanning Mobility Particle Sizer model 3934 
(SMPS, consisting of a Classifier model 3071 and a Condensation particle counter model 3022A, TSI Inc., St. Paul, MN, USA) to detect an increase in particle size that would suggest condensation of NMP vapour onto the sodium chloride particles. A portable fan mixed the air inside the chamber and the pressure was kept at approximately $2 \mathrm{~Pa}$ above the ambient pressure.

\subsection{Air monitoring}

Three different methods were used for the exposure assessment of NMP. In the first method, a single solid adsorbent tube connected to a pump was used (Amberlite XAD-7, SKC pumps, $0.21 / \mathrm{min})$. In the second method, two serial coupled solid adsorbent tubes (Amberlite XAD-7) separated by a glass fibre filter (SKC type AE filters) were used (SKC pumps, $0.21 / \mathrm{min}$ ). In the third method, a glass tube coated with active carbon, a socalled denuder ( $\mathrm{L}=150 \mathrm{~mm}, \varnothing=7 \mathrm{~mm}$ ), coupled to an active carbon filter was used (SKC pumps, $0.2 \mathrm{l} / \mathrm{min}$ ). The two methods including solid sorbent tubes were used in four $2-\mathrm{h}$ sampling periods while the denuders were used in two 4-h sampling periods.

\subsection{Study Design}

The volunteers were exposed in the chamber for $8 \mathrm{~h}$, three at a time. They were exposed at four different occasions with one week apart. The RH was either low at $24-33 \%$ or high at $68-88 \%$. The air concentrations of NMP were either 0 or approximately 20 $\mathrm{mg} / \mathrm{m}^{3}$ (low RH range 19-23 mg NMP/m³ ; high RH range $16-18 \mathrm{mg} \mathrm{NMP} / \mathrm{m}^{3}$ ). The 
added amount of NMP was constant with a theoretical air level of approximately 21 $\mathrm{mg} / \mathrm{m}^{3}$. No chamber settings were changed between the different exposure sessions, except for the humidity and the temperature of the air. The mean temperature at the lower $\mathrm{RH}$ was $24.7^{\circ} \mathrm{C}$ (Coefficient of variation (CV) $5 \%$ ) while that at the high $\mathrm{RH}$ was 25.9 (CV $4 \%$ ). This difference was statistically significant. The volunteers were dressed in a cotton t-shirt and a pair of cotton trousers, supplied by the authors. At 2, 4 and $6 \mathrm{~h}$ after the start of exposure, the subjects left the chamber for 10-15 minutes for sample collection and a brief medical examination.

The initial hypothesis was that we would find an increased NMP uptake after exposure to the same levels of NMP in humid air compared to dry air, because the increased amount and size of particles in the aerosol would also increase the dermal absorption. Therefore, sodium chloride particles were introduced into the chamber during the exposure in humid air only, to facilitate NMP-particle formation by condensation and to maximize the difference of the gas/particle ratio between the two humidity levels.

\subsection{Biological samples}

Blood samples $(20 \mathrm{ml})$ were collected in evacuated tubes containing heparin (Venoject, Teruma Europe NV, Leuven, Belgium), by venopuncture, immediately before the start of exposure, and at 2, 4, 6, 8, 10, 12, 24, 32, 48 and $72 \mathrm{~h}$ after the start of exposure. The blood was allowed to cool to room temperature and then centrifuged at $1500 \mathrm{~g}$ for 10 min. The plasma was transferred to polyethylene test tubes and frozen at $-20^{\circ} \mathrm{C}$ until analysis. 
All urine voided was collected. Urine was collected before the start of exposure and at $2,4,6,8,10,12,16,24,36,48,72,96$ and $120 \mathrm{~h}$ after the start of exposure. At every time point, the total urine volume excreted was determined before $30 \mathrm{ml}$ was transferred to polyethylene test tubes and frozen at $-20^{\circ} \mathrm{C}$ until analysis. To calculate urine concentrations adjusted to urine density, the following formula was used:

$$
C(\text { corr })=\frac{C(\text { obs }) *(1.016-1)}{(\rho-1)}
$$

where $C($ corr $)$ is the corrected concentration, $C(o b s)$ is the observed concentration, $\rho$ is the specific density and 1.016 is an assumed average density reported by Boeniger et al. (1993). The creatinine concentrations were analysed according to an enzymatic method described by Mazzachi et al. (2000).

\subsection{Analysis of NMP in air}

The air samples were analysed according to Åkesson and Paulsson (1997). NMP was desorbed from the solid adsorbent with $2 \mathrm{ml}$ of a mixture of $5 \%$ ethanol in ethyl acetate. For the analysis of the sheets of active carbon used for the denuders and filters, 5 and 3 $\mathrm{ml}$, respectively, was used. After $2 \mathrm{~h}$ of shaking, the organic phase was transferred into glass vials with polyfluorotetraethylene (PFTE) screw caps. NMP was analysed with a Varian gas-liquid chromatograph (Varian 3700; autosampler 8035) with a nitrogen phosphorus detector (NPD; Varian TSD). A fused silica column (30 m x $0.25 \mathrm{~mm}, 0.25$ $\mu \mathrm{m}$ DB-5MS; J\&W Scientific (Fisons), Folsom, CA, USA) was used. 


\subsection{Analysis of NMP and its metabolites in plasma and urine}

For the determination of NMP and its metabolites in both plasma and urine, a method previously described by Carnerup et al. (2001) was used with minor changes. The method was extended and validated to include NMP, MSI and 2-P. Samples were prepared by adding $50 \mu \mathrm{l}$ of deuterium-labelled internal standard of each compound, except for 2-P, to $1.0 \mathrm{ml}$ of plasma or urine. The samples were then added to Isolute ENV+ solid phase extraction columns, previously conditioned with $5 \mathrm{ml}$ of methanol and $10 \mathrm{ml}$ of water. The columns were washed with $1 \mathrm{ml}$ of water, dried by air suction for $5 \mathrm{~min}$ and then centrifuged at $1500 \mathrm{~g}$ for $15 \mathrm{~min}$. NMP and its metabolites were then extracted with $2 \mathrm{ml}$ of an 8:2 mixture of ethyl acetate and ethanol. The extracts were dried under a nitrogen stream and then dissolved in $1.0 \mathrm{ml}$ of water with $0.5 \%$ acetic acid. The samples were transferred into $2 \mathrm{ml}$ glass vials and analysed using liquid chromatography coupled to a tandem mass spectrometer (LC-MS/MS). Instead of using electrospray ionisation (ESI) as previously described, atmospheric pressure chemical ionisation (APCI) in the positive ion mode was used.

The within-day precision was calculated as the relative standard deviation (RSD) of 10 samples spiked to $0.5 \mu \mathrm{g} / \mathrm{ml}$ and 10 samples spiked to $25 \mu \mathrm{g} / \mathrm{ml}$. One sample spiked to $0.5 \mu \mathrm{g} / \mathrm{ml}$ and one sample spiked to $25 \mu \mathrm{g} / \mathrm{ml}$ was analysed five times over a couple of weeks for the determination of the between-day precision. The studied mass fragments $\mathrm{m} / \mathrm{z}$ (precursor ion/fragment ion), the limits of detection, the within-day and between-day precisions are presented in Table 1. 
2.8. Toxicokinetic calculations

The trapezoidal rule was used for the calculation of the area under the plasma concentration-time curve (AUC; Rowland and Tozer, 1995).

\subsection{Statistics}

Mann-Whitney U test were used for unpaired comparisons between groups and Wilcoxon signed-rank test were used for paired comparisons between groups. 


\section{Results}

The median air levels of NMP in air from the three different methods used are shown in Table 2. In all methods, more than $95 \%$ of the NMP was found in the first sampling device. No significant differences were found in the air levels between the different methods. There was significant difference between the exposure levels in dry and humid air. There was no formation of larger particles during the exposure, than those of the generated sodium chloride particles. The generated particles had a concentration in the chamber of 3000-6000 particles $/ \mathrm{cm}^{3}$ and showed a unimodal size distribution with a geometric mean diameter of $0.2 \mu \mathrm{m}$.

The individual, accumulated excretions of the sum of NMP and its metabolites in urine are shown in Fig. 1 for the exposure in dry air and humid air as a function of the air levels. In this figure results from the study by Jönsson and Åkesson (2003) are also included for comparison. The mean total accumulated excretion was $7 \%$ (median $12 \%$ ) higher in humid air than in dry air but this difference was not statistically significant. The difference was even higher (mean $24 \%$ ) when the individual exposure levels according to methods 1 or 2 were taken into account. The group median total excreted amounts in urine of each metabolite are shown in Table 3. The mean fractions of unchanged NMP excreted in urine corresponded to $1.3 \%$ of the total amount excreted as NMP or the metabolites. The corresponding fractions for 5-HNMP were 55-57 \%, for MSI 1.5-1.6 \%, for 2-HMSI 39-40 \% and for 2-P 1.4-1.5\%. There were no differences in the urinary median peak concentrations for NMP and its metabolites between the exposures in dry and humid air (Table 4). 
The AUC for NMP and its metabolites are shown in Table 3. There were no differences in the plasma median peak concentrations for NMP and its metabolites between the exposures in dry and humid air (Table 4). There were no NMP, 5-HNMP, MSI or 2-HMSI in either plasma or urine from the exposures at $0 \mathrm{mg} \mathrm{NMP} / \mathrm{m}^{3}$. The concentrations in the $24 \mathrm{~h}$ samples are shown in Table 4 for both plasma and urine for comparison.

2-P was found in both plasma and urine. However, the levels in plasma were so low that quantification was difficult in most samples. In urine, an irregular peak was found 8-12 $\mathrm{h}$ after the start of exposure. The irregularities decreased after adjustment to creatinine but were almost completely eliminated after adjustment to urine density. In some of the subjects, 2-P in low concentrations was also present in urine before the start of exposure. The levels of 2-P in urine adjusted for density during NMP exposure in dry and humid air are shown in Fig. 2. 


\section{Discussion}

This study shows no statistically significant increased excretion of NMP and its metabolites after the exposure of NMP in humid air compared to exposure in dry air but there were large individual differences. In addition, the metabolite 2-P, previously found in rats, was confirmed to be a human metabolite of NMP exposure.

Three methods for the assessment of the NMP levels in air were applied. It was assumed that the adsorbent tubes should collect the vapour and at least some of the particles. The approach to put a filter and a second adsorbent tube behind the first sampling tube were performed to elucidate if some particles could pass through the first adsorbent tube. However, only small amounts of NMP were found on the filter for exposures both in humid and dry air. Furthermore, the denuder was supposed to sample the NMP vapour while the particles were thought to be sampled on the filter. However, almost all NMP was found in the denuder for both humid and dry air. It is likely to draw the conclusion that there were virtually no particles containing NMP in the air of the chamber in either case. This is also supported by the fact that there was no formation of larger particles during the exposure in humid air shown by the SMPS measurements. Thus, the initial aim for this investigation, to study the uptake of NMP after exposure in air with various ratios of vapour and particles, was abandoned.

The performance of the exposure chamber was not optimal for this kind of study. It was not possible to maintain a stable humidity of more than $85 \% \mathrm{RH}$, without rising the temperature inside the chamber to, for the subjects, uncomfortable levels. The aim for the study was therefore adapted to the equipment and changed to study the absorption of 
NMP in humid and dry air. The question whether the relative humidity itself have an impact of the absorption is of importance since animal experiments have shown on differences in symptoms during exposure in humid and dry air (IPCS, 2001).

Jönsson and Åkesson (2003) showed only a small variation between six individuals in the accumulated excretion of NMP and its metabolites during exposure to 10 and 25 $\mathrm{mg} \mathrm{NMP} / \mathrm{m}^{3}$ in rather dry air. The results in the present study indicate a similar pattern in five of the subjects. However, the sixth subject showed a somewhat larger elimination. The similarities in biological levels in the two studies should be noted as shown in Fig. 1.

There seemed to be larger individual differences in the excretion during the exposure in humid air than in dry air. This may indicate a small increase in the absorption of NMP during exposure in humid air in some of the individuals. Such a difference could be caused by an increase in dermal absorption or due to an increased breathing rate during the exposure in humid air. The temperature in the chamber was higher in humid than in dry air which could lead to a higher breathing rate (Fox et al. 1991). On the other hand, in the study by Jönsson and Åkesson (2003) approximately $100 \%$ of the estimated inhaled dose was recovered as NMP or its known metabolites. Since it has been determined that only $65 \%$ of an oral NMP dose ( $\AA$ kesson and Jönsson, 1997) was found in urine as NMP and metabolites, this could imply that NMP exposure even in dry air could lead to a dermal absorption corresponding to the remaining $35 \%$.

We could not show a statistically significant increase in the total cumulated excretion of NMP and its metabolites in urine after exposure in humid air as compared to dry air. Furthermore, there were no differences in the levels of peak concentrations, neither in urine nor in plasma. Also, no differences were obvious when comparing the 
AUC:s. However, the large individual difference in the excretion of NMP and its metabolites in humid air still support the use of biological monitoring for assessment of NMP exposure.

In this study 2-P was confirmed to be a metabolite after NMP exposure to human volunteers. Previously 2-P has been described as a metabolite after NMP exposure to rats (Carnerup et al., manuscript). The compound is probably formed by de-methylation of NMP. 2-P is therefore not a part of the previously known metabolic chain, which includes 5-HNMP, MSI and 2-HMSI. The origin of the 2-P in urine before the start of exposure is unknown. It has been described that some pharmaceuticals are metabolised to 2-P (Lundgren and Fales, 1980; Ogiso et al., 1998) but none of the volunteer took such drugs.

2-P has been described to be a reproductive toxic compound inducing developmental abnormalities on the musculoskeletal and gastrointestinal systems on foetuses (National Technical Information Service). Thus, it is possible that the reproductive toxic effects of NMP are caused by metabolism into 2-P or one of its metabolites. On the other hand, it is also possible that 2-P is methylated in the body and that it is NMP or one of its metabolites that are the toxic compound.

As a conclusion, we could not show a statistically higher absorption of NMP and its metabolites after exposure to NMP in humid air than in dry air. However, there were large individual differences in the excretion, especially for the exposure in humid air. This supports the use of biological monitoring for exposure assessments. In addition, 2-P was confirmed to be a human metabolite of NMP. This may be of importance for the developmental toxicity of NMP. 


\section{Acknowledgements}

This work was supported by the Swedish Council for Work Life Research, the Swedish Research Council and the Medical Faculty at Lund University. Dr Gunilla Weislander, Uppsala is acknowledged for her medical supervision of the subjects. 


\section{References}

Åkesson, B., Carnerup, M.A., Jönsson, B.A.G., 2004. Evaluation of exposure biomarkers from percutaneous absorption of $N$-methyl-2-pyrrolidone. Scand. J. Work Environ. Health 30, 306-312.

Åkesson, B., Jönsson, B.A.G., 1997. Major metabolic pathway for $N$-methyl-2pyrrolidone in humans. Drug. Metab. Dispos. 25, 267-269.

Åkesson, B., Jönsson, B.A.G., 2000. Biological monitoring of $N$-methyl-2-pyrrolidone using 5-hydroxy- $N$-methyl-2-pyrrolidone in plasma and urine as the biomarker. Scand. J. Work Environ. Health 26, 213-218.

Åkesson, B., Paulsson, K., 1997. Experimental exposure of male volunteers to $N$-methyl2-pyrrolidone (NMP): acute effects and pharmacokinetics of NMP in plasma and urine. Occup. Environ. Med. 54, 236-240.

Akrill, P., Cocker, J., Dixon, S., 2002. Dermal exposure to aqueous solutions of $N$ methylpyrrolidone. Toxicol Lett 134, 265-269.

Anundi, H., Langworth, S., Johanson, G., Lind, M.-L., Åkesson, B., Friis, L., Itkes, N., Söderman, E., Jönsson, B.A.G., Edling, C., 2000. Air and biological monitoring of solvent exposure during graffiti removal. Int. Arch. Occup. Environ. Health 73, 561-569. 
Becci, P.J., Knickerbocker, M.J., Raegan, E.L., Parent, R.A., Burnette, L.W., 1982. Teratogenicity study of $\mathrm{N}$-methylpyrrolidone after dermal application to Sprague-Dawley rats. Fundam. Appl. Toxicol. 2, 73-76.

Beaulieu, H.J., Schmerber, K.R., 1991. M-Pyrol ${ }^{\mathrm{TM}}$ (NMP) use in the microelectronics industry. Appl. Occup. Environ. Hyg. 6, 874-880.

Boeniger, M.F., Lowry, L.K., Rosenberg, J., 1993. Interpretation of urine results used to assess chemical exposure with emphasis on creatinine adjustments: A review. Am. Ind. Hyg. Assoc. J. 54, 615-627.

Bower, D.B., 1997. Letters to the Editor: Stillbirth after occupational exposure to $\mathrm{N}$ methyl-2-pyrrolidone. J. Occup. Environ. Med. 39, 303-304.

Carnerup, M.A., Saillenfait, A.M., Jönsson, B.A.G., Concentrations of $N$-methyl-2pyrrolidone (NMP) and its metabolites in plasma and urine following oral administration of NMP to rats. (manuscript).

Carnerup, M.A., Åkesson, B., Jönsson, B.A.G., 2001. Determination of 5-hydroxy- $N$ methyl-2-pyrrolidone and 2-hydroxy- $N$-methylsuccinimide in human plasma and urine using liquid chromatography-electrospray tandem mass spectrometry. J. Chromatogr. B. $761,107-113$ 
Fox, G.P.P., O'Regan, M., Matthews, T.G., 1991. The influence of ambient temperature on some commonly measured physiological variables in infants. Ir. J. Med. Sci. 160, 249250.

International Program on Chemical Safety (IPCS, 2001). No.35 N-methyl-2-pyrrolidone. World Health Organization, Geneva.

Jönsson, B.A.G., Åkesson, B., 1997. Determination of $N$-methylsuccinimide and 2hydroxy- $N$-methylsuccinimide in human urine and plasma. J. Chromatogr. B. 704, 151158.

Jönsson, B.A.G., Åkesson, B., 2001. $N$-Methylsuccinimide in plasma and urine as a biomarker of exposure to $N$-methyl-2-pyrrolidone. Int. Arch. Occup. Environ. Health. 74, 289-294.

Jönsson, B.A.G., Åkesson, B., 2003. Human experimental exposure to $N$-methyl-2pyrrolidone (NMP): toxikokinetics of NMP, 5-hydroxy- $N$-methyl-2-pyrrolidone, $\mathrm{N}$ methylsuccinimide and 2-hydroxy- $N$-methylsuccinimide (2-HMSI), and biological monitoring using 2-HMSI as a biomarker. Int. Arch. Environ. Health. 76, 267-274.

Langworth, S., Anundi, H., Friis, L., Johanson, G., Lind, M.-L., Söderman, E., Åkesson, B.A., 2001. Acute health effects common during graffiti removal. Int. Arch. Occup. Environ. Health. 74, 213-218. 
Ligocka, D., Lison, D., Haufroid, V., 2003. Contribution of CYP2E1 to N-methyl-2pyrrolidone metabolism. Arch. Toxicol. 77, 261-266.

Lundgren, D.W., Fales, H.M., 1980. Metabolism of putrescine to 5-hydroxy-2pyrrolidone via 2-pyrrolidone. J. Biol. Chem. 255, 4481-4486.

Mazzachi, B.C., Peake, M.J., Ehrhardt, V., 2000. Reference range and method comparison studies for enzymatic and Jaffé creatinine assays in plasma and serum and early morning urine. Clin. Lab. 46, 53-55.

Miller, J.C., Miller, J.N., 1984. Statistics for Analytical Chemistry, Ellis Horwood, Chichester, UK.

National Technical Information Service, http://www.cdc.gov/niosh/rtecs/uy573438.html.

Ogiso, T., Iwaki, M., Tanino, T., Ikeda, K., Paku, T., Horibe, Y., Suzuki, H., 1998.

Pharmacokinetics of aniracetam and its metabolites in rats. J. Pharm. Sci. 87, 594-598.

Rowland, M., Tozer, T.N., 1995. Clinical pharmacokinetics: concepts and applications $3^{\text {rd }}$ ed., Lippincott Williams \& Wilkins, Philadelphia, PA, USA. 
Saillenfait, A.M., Gallissot, F., Langonné, I., Sabaté, J.P., 2002. Developmental toxicity of $N$-methyl-2-pyrrolidone administered orally to rats. Food Chem. Toxicol. 40, 17051712 .

Saillenfait, A.M., Gallisso, F., Morel, G., 2003. Developmental toxicity of $N$-methyl-2pyrrolidone in rats following inhalation exposure. Food Chem. Toxicol. 41, 583-588.

Solomon, G.M., Morse, E.P., Garbo, M.J., Milton, D.K., 1996. Stillbirth after occupational exposure to $N$-methyl-2-pyrrolidone. J. Occup. Environ. Med. 38, 705-713. 


\section{Legends}

Fig. 1. The individual, accumulated excretions of the sum of NMP and its metabolites as a function of air levels of NMP. The results from dry air (daily mean values of Methods 1 and 2) are denoted $(\bullet)$ and for humid air $(\bullet)$. Results from the exposures at 10 and 25 $\mathrm{mg} / \mathrm{m}^{3}$ in the study by Jönsson and Åkesson (2003) are included in the figure and denoted (०).

Fig. 2. The mean levels of 2-P in urine after adjustment for density during NMP exposure in dry $(\bullet)$ and humid air $(\mathbf{\square})$. 
Table 1

The limit of detection (LOD) and the variations of the within-day precision $(n=10)$ and between-day $(\mathrm{n}=5)$ precision for NMP and its metabolites. The variations of the precisions are presented as the relative standard deviation (RSD).

\begin{tabular}{lccccc}
\hline Compound & Fragment & Matrix & LOD & $\begin{array}{c}\text { Within-day } \\
\text { precision }\end{array}$ & $\begin{array}{c}\text { Between-day } \\
\text { precision }\end{array}$ \\
& $\mathbf{( m / \mathbf { z } )}$ & & $\mathbf{( n g / m l )}$ & $\mathbf{( \% )}$ & $\mathbf{( \% )}$ \\
\hline NMP & $100 / 58$ & Plasma & 19 & $2-3$ & $5-11$ \\
5-HNMP & $116 / 58$ & Plasma & 44 & $1-5^{*}$ & $3-5^{*}$ \\
5-HNMP & $116 / 85$ & Plasma & 11 & $1-4^{*}$ & $5^{*}$ \\
MSI & $114 / 58$ & Plasma & 11 & $2-3$ & $4-12$ \\
2-HMSI & $130 / 58$ & Plasma & 62 & $3-6^{*}$ & $3-6^{*}$ \\
2-P & $86 / 44$ & Plasma & 62 & $6-8$ & $5-23$ \\
\hline NMP & $100 / 58$ & Urine & 3.6 & $3-4$ & $4-12$ \\
5-HNMP & $116 / 58$ & Urine & 44 & $2-10^{*}$ & $4-12^{*}$ \\
5-HNMP & $116 / 85$ & Urine & 12 & $2-12^{*}$ & $4-6^{*}$ \\
MSI & $114 / 58$ & Urine & 6 & $3-4$ & $3-6$ \\
2-HMSI & $130 / 58$ & Urine & 62 & $3-10^{*}$ & $7-8^{*}$ \\
2-P & $86 / 44$ & Urine & 62 & $4-5$ & $4-5$
\end{tabular}

\footnotetext{
${ }^{*}$ The precisions reported for 5-HNMP and 2-HMSI have previously been reported by Carnerup et al. (2001)
} 
Table 2

The time-weighted mean NMP air levels (range, $\mathrm{mg} / \mathrm{m}^{3}$ ) obtained for each day of exposure, using three different methods for the assessment of NMP in dry and humid air.

\begin{tabular}{lcccc}
\hline Air humidity & Day & Method 1 $^{*}$ & Method 2 $^{\dagger}$ & Method 3 $^{\ddagger}$ \\
\hline $20 \%$ RH & 1 & $19(15-21)$ & $19(19-20)$ & $21(20-21)$ \\
& 2 & $21(20-22)$ & $20(18-22)$ & $24(23-26)$ \\
$80 \%$ RH & 1 & $18(15-19)$ & $18(15-20)$ & $16(16-17)$ \\
& 2 & $16(16-17)$ & $16(15-16)$ & $15(14-16)$
\end{tabular}

* Single adsorbent tube as described in Section 2.3

${ }^{\dagger}$ Two serial coupled adsorbent tubes, separated by a glass fibre filter as described in Section 2.3

Denuder coupled to an active carbon filter as described in Section 2.3 
Table 3

Median accumulated excreted amounts (range) and median AUC:s (range) for NMP and its metabolites after exposure to NMP in dry air (group 1) and humid air (group 2).

\begin{tabular}{lccc}
\hline Analyte & Group & $\begin{array}{c}\text { Excreted amount } \\
(\boldsymbol{\mu m o l})\end{array}$ & $\begin{array}{c}\text { AUC } \\
(\boldsymbol{\mu m o l} * \mathbf{h} / \mathbf{l})\end{array}$ \\
\hline NMP & 1 & $9.0(6.9-33)$ & $113(91-124)$ \\
NMP & 2 & $14(5.0-17)$ & $119(58-313)$ \\
5-HNMP & 1 & $505(457-809)$ & $292(223-334)$ \\
5-HNMP & 2 & $589(440-822)$ & $275(193-443)$ \\
MSI & 1 & $14(8.4-28)$ & $76(53-114)$ \\
MSI & 2 & $15(6.1-27)$ & $86(44-172)$ \\
2-HMSI & 1 & $362(340-486)$ & $195(94-229)$ \\
2-HMSI & 2 & $375(306-618)$ & $194(137-470)$ \\
2-P & 1 & $11(8.5-28)$ & NQ ${ }^{*}$ \\
2-P & 2 & $13(11-22)$ & NQ \\
\hline
\end{tabular}

${ }^{*} \mathrm{NQ}=$ Not possible to quantify 
Table 4

The median peak concentrations ( $\mu \mathrm{mol} / \mathrm{l}$; range), peak times ( $\mathrm{h}$; range), half-lives ( $\mathrm{h}$; range) and median concentrations ( $\mu \mathrm{mol} / \mathrm{l}$; range) $24 \mathrm{~h}$ after the start of exposure, obtained for NMP and its metabolites after exposure to NMP in dry (group 1) and humid air (group 2).

\begin{tabular}{|c|c|c|c|c|c|c|c|c|c|}
\hline \multirow[t]{2}{*}{ Analyte } & \multirow[t]{2}{*}{ Group } & \multicolumn{4}{|l|}{ Plasma } & \multicolumn{4}{|l|}{ Urine } \\
\hline & & Conc at $t_{\max }$ & $\mathbf{t}_{\max }$ & $\mathbf{t}^{1 / 2}$ & Conc at $24 \mathrm{~h}$ & Conc at $\mathbf{t}_{\max }{ }^{*}$ & $\mathbf{t}_{\max }$ & $t^{1 / 2}$ & Conc $16-24 h^{*}$ \\
\hline \multirow[t]{2}{*}{ NMP } & 1 & $10(9.2-12)$ & $8(6-8)$ & $3.3(2.6-3.6)$ & $0.31(0.16-0.47)$ & $12(11-19)$ & $6-8(4-8)$ & $3.7(2.9-4.2)$ & $0.77(0.41-0.91)$ \\
\hline & 2 & $9.7(5.2-32)$ & $8(4-8)$ & $3.2(2.6-4.6)$ & $0.40(0.12-0.67)$ & $13(9.8-17)$ & 8-10 (6-10) & $3.9(2.0-4.1)$ & $0.81(0.20-1.14)$ \\
\hline \multirow[t]{2}{*}{ 5-HNMP } & 1 & $15(13-18)$ & $10(8-12)$ & $7.1(4.7-8.0)$ & $4.3(2.8-6.1)$ & 649 (598-977) & $10-11(6-12)$ & $7.4(5.7-7.7)$ & $253(201-417)$ \\
\hline & 2 & $15(10-23)$ & $10(8-12)$ & $7.9(4.9-8.6)$ & $4.7(3.1-7.9)$ & $625(498-1328)$ & $8-9(6-12)$ & $7.6(5.3-8.4)$ & $294(217-514)$ \\
\hline \multirow[t]{2}{*}{ MSI } & 1 & $5.0(3.2-7.2)$ & $12(12)$ & $4.6(3.4-16)$ & $1.7(0.59-2.3)$ & $10(6.5-21)$ & $10-11(6-16)$ & $9.4(6.1-13)$ & $5.9(5.3-9.9)$ \\
\hline & 2 & $5.0(2.0-6.9)$ & $12(10-12)$ & $9.9(5.9-19)$ & $2.5(1.0-4.4)$ & 8.7 (6.9-27) & $11-12(6-16)$ & $8.4(5.7-11)$ & $6.3(3.6-9.9)$ \\
\hline \multirow[t]{2}{*}{ 2-HMSI } & 1 & $4.8(2.7-5.3)$ & $24(24-36)$ & $16(8.1-22)$ & $4.6(2.7-5.3)$ & $169(84-244)$ & $24-36(16-36)$ & $18(16-26)$ & $167(84-226)$ \\
\hline & 2 & $4.4(3.3-12)$ & $36(24-36)$ & $18(17-20)$ & $4.2(3.3-12)$ & $176(127-218)$ & $24-36(16-48)$ & $18(15-28)$ & $160(102-218)$ \\
\hline \multirow[t]{2}{*}{ 2-P } & 1 & $\mathrm{NQ}^{\dagger}$ & - & - & - & $14(8.7-22)$ & $11-12(8-12)$ & $6.8(4.6-12)$ & $5.0(4.2-5.6)$ \\
\hline & 2 & NQ & - & - & - & $14(10-20)$ & $10-11(9-12)$ & $8.6(7.4-12)$ & $5.3(4.8-9.1)$ \\
\hline
\end{tabular}

Concentrations for 5-HNMP and 2-HMSI are adjusted to the urine density.

${ }^{\dagger} \mathrm{NQ}=$ Not possible to quantify 
Fig. 1.

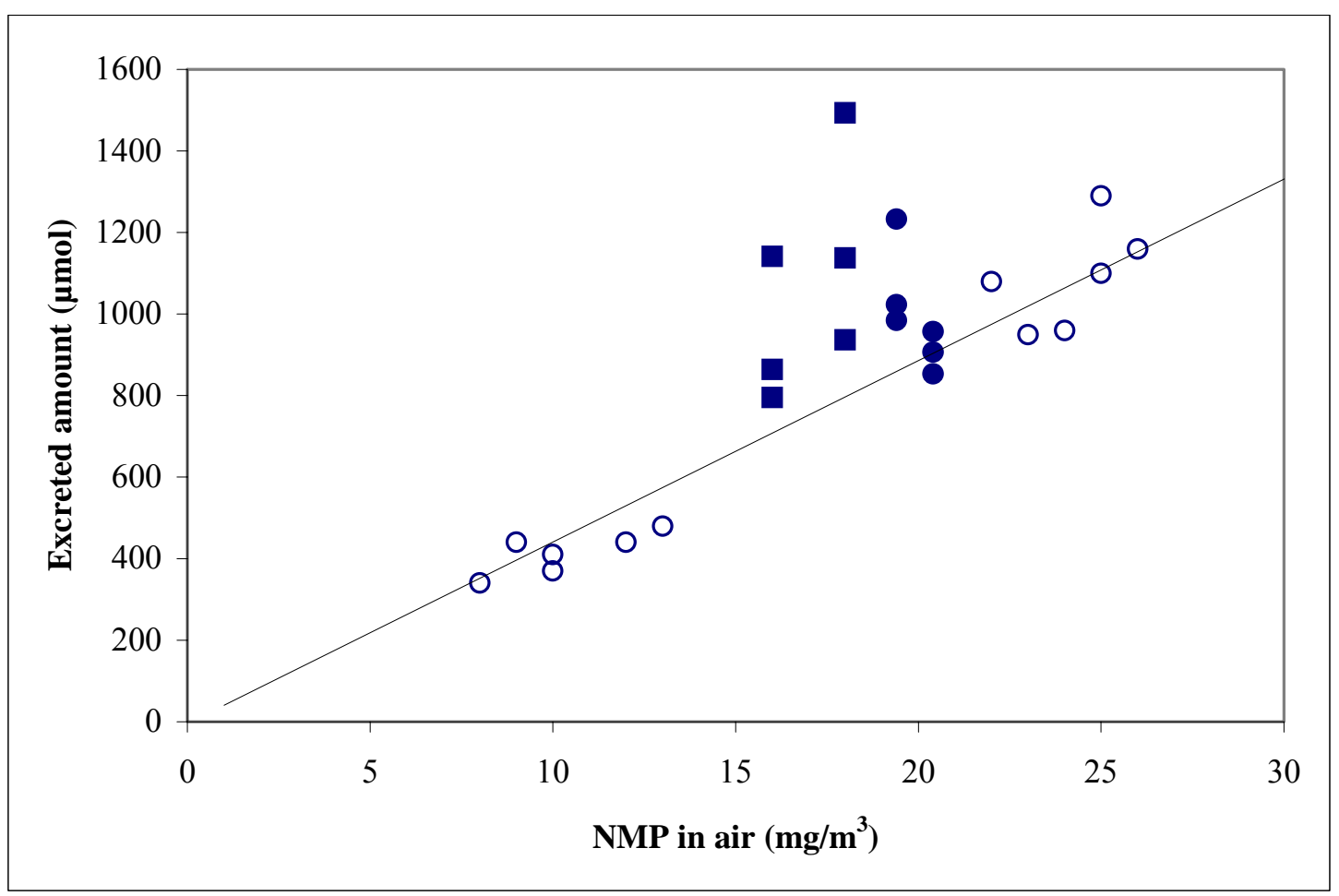

Fig. 2.

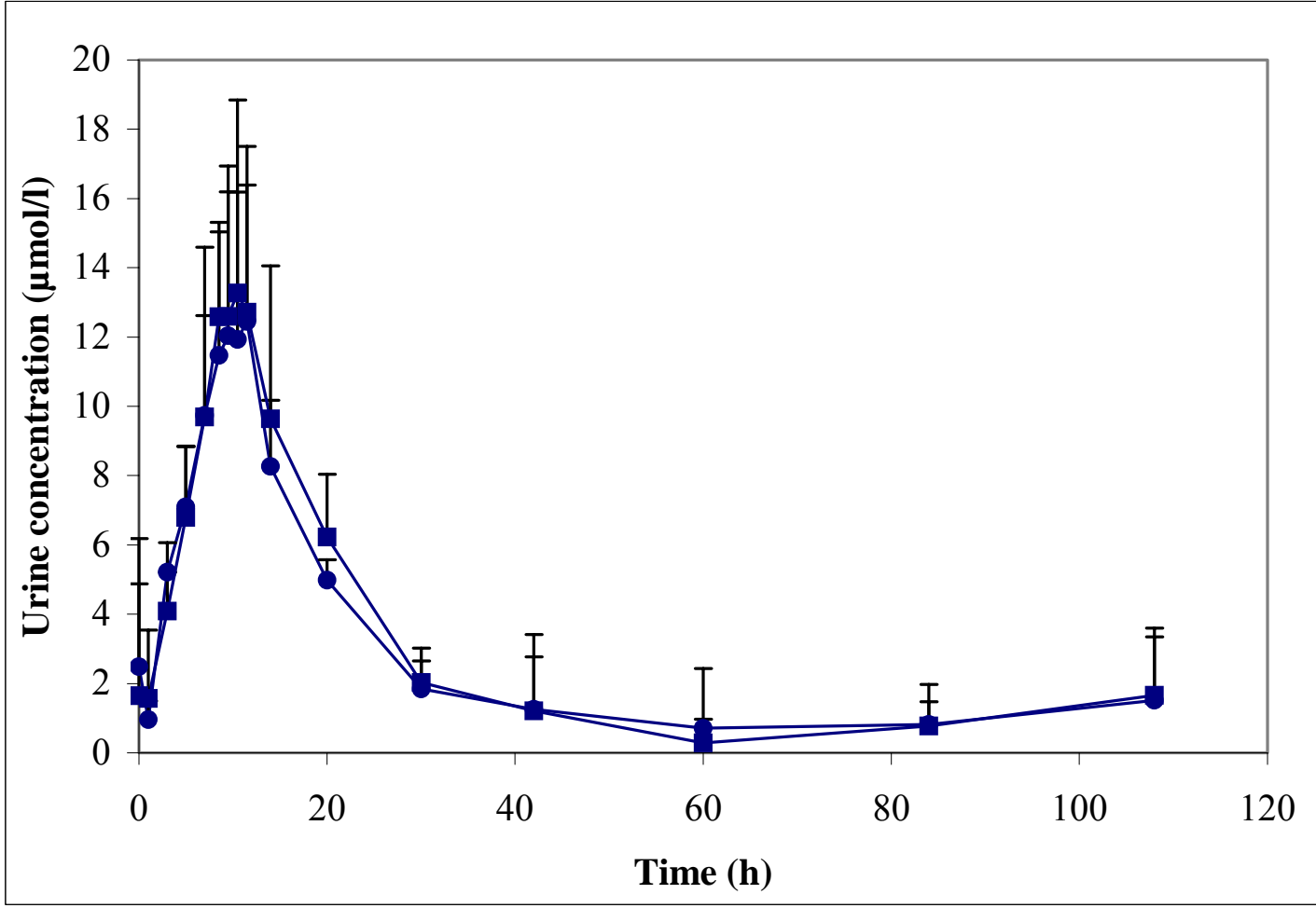

